\title{
Marriage Concept of Japanese Urban Female from A Woman of Thirty
}

\author{
Ping Zhao \\ School of Foreign Languages, Dalian Jiaotong University, Dalian, 116028, China
}

Keywords: marriage concept; low birth rate; late marriage; happiness

\begin{abstract}
A Woman of Thirty mainly introduces two different kinds of women, one is those with achievements, and the other is housewives, who have various problems in the way to marriage. This paper is to discuss the marriage concept of Japanese urban female from this aspect and reveal the background and reason for marriage migration, attempting to find out the solutions of various problems brought by marriage and the enlightenment brought to us.
\end{abstract}

\section{Introduction}

The novel A Woman of Thirty describes a woman Naoko who is successful in career. Although she is more than 30 , she has the temper and charm that women of twenties do not have and are attractive to men. But none of these men conform to the image of a qualified husband in the impression of Naoko. Due to emotional emptiness, she communicates with several different types of men continuously. In the previous section, the novel mainly introduces the things without result between Naoko and Heese. Actually Heese might fall in love with Naoko in that way, but she refuses the love near at hand in a reserved and cold manner and only maintains the relation of "bed partner”. Later, when meeting her really love Sawaki who has a wife, she feels it is too late, so there appears extramarital affair, and there is the tangling between Sawaki and his wife Eriko. The ending of the story is that both kinds of women do not get their happiness. Naoko becomes the third party to destruct others' family, even if she resists the public opinion and pressure, and resists the crazy revenge of Eriko, she cannot escape the worm of conscience, Eriko commits suicide by opening her bowel, with a 6 months' pregnant child. The social condemn to her makes her abandon the object with who she can marry, resign from the work that others admire, and her parents also have their life influenced, suffering from the attack of the public opinion.

Why is the marriage ending of a rational and intelligent occupational female lie this? Why does an understanding wife and loving mother have such a destiny?

\section{Reasons for marriage concept of modern Japanese urban women}

In terms of the national habit of Japan, marriage is not emphasized so much, and there is strong awareness of age for marriage. Even if in such a traditional background, there are still more and more young women avoiding marriage, most of whom think that they "do not want to lose freedom and relaxing", so they have strong resistance to marriage. They hope that their husbands can participate in the society and undertake the housework jointly, and at least give comfort and thanks for their holiday and remuneration-free labor at home. They are searching for a "mature and equal partner and marriage" that can make them do things at their will, but seldom men conform to this requirement. And this may be one of the important reasons why there are more and more single occupational women in the current Japanese society.

Although most of today's young men in Japan support the women's advocacy of employment, equal treatment between men and women and joint undertaking housework by husband and wife in concept, the social system of "men orientation" has not been changed in nature, there is still a gap between the young husband and role expectation of modern wives, and there is even a lack of quality of partner couple role, so there is staggering of role expectation between both side, and it also causes the increasing of extramarital love of young men and many young women are additive to gambling and even mental abnormality. Perhaps this is the reason why another heroine Eriko in the novel A Women of Thirty suffers from mental diseases and postnatal depression. In others' 
opinion, the husband Sawaki loves his husband very much, but actually, he often exercises mental violence and attacks his wife in words. However, the wife does not leave her husband, because without husband, she cannot survive in the society. This indicates that the Japanese is in the economic bubble period, many women suffer from great pressure in work and the danger of being fired, and some women are married to the position of family. However, just like that economy decides position, the wives without economic source rely on husbands, and can only be fallen into the emotional slave of husband and have no status and self-esteem at home. Even if husbands say that they do not love them, and are unwilling to live with them, they are unwilling to divorce even if die. Without husbands, they also cannot survive.

\section{Influence of modern female marriage concept on Japanese society and women}

I think the marriage of modern women has the following five influences on the society and women:

First, the female status has been improved. The women have been liberated from family restriction and begin to be active in the society. Take the Japanese female politicians as an example, the proportion change of female representatives of House of Representatives in Japan is as follows: increase from 8 representatives accounting for $1.7 \%$ to 9 representatives accounting for $8.9 \%$ in 1980, 12 accounting for 2.3\% in 1990, 35 accounting for $7.3 \%$ in 2000, 7.1\% accounting for 24 in 2003 and 43 accounting for 43 in 2005. The proportion change of female representatives of senate is as follows: increase from 12 accounting for $4.8 \%$ in 1950, 17 accounting for $6.7 \%$ in 1980, 37 accounting for $14.7 \%$ in 1992, 38 accounting for $15.4 \%$ in 2001, 33 accounting for $13.6 \%$ in 2004 and 42 accounting for $17.4 \%$ in 2007 . Although there is still a large gap compared with the male representatives, the proportion of female politicians indeed has increased. They can reflect the females' idea to the congress. In 2010, the Japanese female representative Renho obtained the support of record-breaking 1.7 million votes in the senate, and she was the only candidate with number of voting more than 1 million. Her being reelected consolidated her status of being one of the most politicians in Japan.

Second, in employment, in the past many companies were unwilling to admit women, and stipulated that women should retire 5 years earlier than men. With the passing of "equal employment act", the number of employed women in Japan increased from 11.67 million accounting for $32 \%$ of the total population in 1975 to 15.18 million accounting for $35.3 \%$ of the total population in 1984 and to $50.4 \%$ in 1997. At the same time, more and more women have entered the "traditional field" of men. In 2010, the Central Bank of Japan appointed the 45-year-old Tokiko Shimizu as the first female branch president in its 128 years' history, and in the same year, 42-year-old Ari Fuji was appointed as the aircraft commander by JAL under JAL Express Co., becoming the first female aircraft commander in Japanese aviation industry. And East Japan Railway also had the first female station agent in Tokyo Station.

Third, the education enrollment rate is increased. In the 1960s, the school-age females receiving university education (including short-term university) only accounted for $5.5 \%$, while this proportion increased to $32.5 \%$ in the middle of the $1970 \mathrm{~s}$, and the gap of enrollment between male and female was shortened rapidly. The female enrollment rate in the 1990 s was $62 \%$, exceeding the proportion of male 59\%. At the end of the 1990s, almost half of the school-age women in Japan could enter university.

Fourth, self-independence. In the past, women did not have the opportunity of working after marriage, so they could not be self-independent. With the independence of females in awareness. They have begun to enter the society and earn wage and can live very well without depending others. The increasing of female's self-independence awareness directly increases the proportion of "being unmarried" and "late marriage and birth", thus causing the reduction of birth rate of Japanese population, and this is the direct reason of low birth rate in the advanced age. In 1975, $90 \%$ of the men and women of 30 years above had been married and the 30-34-year-old unmarried men accounted for $14.3 \%$ and women $7.7 \%$. According to the national situation investigation in 2005, the unmarried rate of Japanese young people has increased continuously, the 30-34-year-old 
unmarried men accounted for $47.1 \%$ and women $32.0 \%$, respectively increasing by $4.8 \%$ and $6 \%$ compared with those in the national situation investigation of 5 years ago. The life-long unmarried rate compared with that of 30 years ago is from $2.1 \%$ (1975) to $15.1 \%$ (2005) for women and $4.3 \%$ (1975) to 6.8\% (2005) for women. The distinctive comparison can indicate that the situation of non-marriage in Japan has been increasingly serious. Especially after the global financial crisis tsunami in 2008, this phenomenon has been more and more highlighted.

The average initial marriage age in Japan was 27.0 for men and 24.7 for women in 1975 and that was $30.1 \%$ for men and $28.3 \%$ for women in 2007 (increasing by 0.1 year compared with the last year on average for men and women). The more and more advanced age of marriage indicates that there is a more significant trend of late marriage. Within about 30 years, the late marriage age has increased by 3.1 years for men and 3.6 years for women/

The postponing of initial marriage age has formed late marriage, which in turn causes the postponing of women's birth age. According to the average birth age of female, the first birth age in 2007 was 29.4 years old, 3.7 years later than that 1975 of 30 years ago. The increasing of birth age will inevitably restrict the birth and birth number, thus late marriage and late birth is also one of the direct reason for the low birth rate.

\section{Thought on the problems existing}

Low birth rate means that the population of Japan in the future will decrease gradually, which will have a lot of negative influences on the social structure and economic development etc. According to the calculation statistics issued by Japanese Economic Planning Agency in June 2000, "during 15 years after 200t, due to the influence of decreased population, the GDP will reduce by $6.7 \%$ ". How to relieve the negative influence of "low birth rate" is a systematic project and key topic involving in politics, economy, culture, society and many other aspects.

\subsection{Government}

After entering the society of "low birth rate", the Japanese government has established a series of laws and regulations to solve the problems of decreased population and low birth rate, for example Basic Direction to Aid Child Policy in the Future (“Angel Plan”) established in December 1994; Low Birth Rate Countermeasures +1 proposed by MHLW in September 2002, which are devoted to establishing the comprehensive measures jointly undertaken by the whole society by starting from the child cultivating families; in July 2003, the congress established Basic Law for Countermeasures for Low Birth Rate Society, established Outline of Countermeasures for Low Birth Rate Society in June 2004 and launched Children and Child Cultivation Aid Plan in December 2004. In the process of establishing these policy laws and regulations, the Japanese government has also constructed "the society of cultivating healthy children" in the countermeasures for low birth rate society and transferred to "the society of being happy for child birth", so as to increase the birth awareness of the Japanese nationals, and on this basis, the countermeasures for low birth rate in Japan have been further strengthened. These policies and laws make the whole Japanese nationals pay attention to "low birth rate" very much, which creates a good social and legal atmosphere to actively discuss how to prevent "low birth rate" effectively. The Japanese government recovers economy actively, in the hope of increasing the nationals' individual income, awards the family having the third child, and provides preference and guarantee for the born children in social guarantee, so as to restore the nationals' birth confidence and increase the number of newborns.

\subsection{Enterprises}

The Japanese enterprises also have taken corresponding countermeasures, for example, extend the child birth holiday period and increase child birth allowance, and some enterprises also guarantee that they will reemploy the female employees who retire for child birth. The enterprises provide such support system mainly based on the experienced female employees, who will cause loss to the companies if resigning for marriage or child birth. To avoid the reduction of labor population, there must be excellent talents. The low birth rate countermeasures of large enterprises reported by the Japanese media include mother holiday system introduced by Nissan Motor, once pregnant, the female employees may stop working temporarily; Tokyo Marine Insurance provides 
that the female employees can shorten three hours' work time before their children are three years old; Itouen increases the child birth allowance; Japanese Sampo guarantees that the female employees will be reemployed after resigning due to birth rate when their children enter primary school; Panasonic and Toshiba etc. provide temporary suspension or holiday system for the female employees to treat infertility.

4.3. Female suggestions

In the traditional Japanese society with work overtime as a virtue, men often have the entertainment like alcohol drinking after work. If they refuse, they will be laughed to be "poor" or "henpecked" by others. Although sometimes men want to go home earlier, they are helpless in front of reality. Therefore, this is not only the female problem, but also a social problem concerning the men in Japan. According to the questionnaire, most of the objects investigated have the following suggestions to solve the problem of "low birth rate":

1. The men themselves do not have the time to care their children and have fewer opportunities to have dinner with family members. In this way, women have more pressure in housework and child care;

2. Advocate that the Japanese men should form the habit of "going home immediately after work and share housework with wives";

3. The Japanese government should strictly implement the "birth holiday" system for male and female employees and guarantee that the employees after birth holiday will return to the original work post;

4. Encourage men to share housework and jointly undertake the responsibilities of raising, educating children and care old people. Especially for the dual-employee family, the community assembly and parents' meeting etc. cannot be shifted to wives completely;

5. Thoroughly cancel the salary difference between men and women;

6. Improve the pension system.

Reconsidering the above issues will bring sense of safety to the married people. The social stability and development need equality between men and women and equal remuneration for the same work. If these problems are improved, the mental pressure of men and women will be decreased naturally, and they will also tend to marry and have children naturally.

\section{Conclusion}

The traditional Japanese culture restricts women at home. The facts prove that marriage is changing, no matter how great contribution and sacrifice women have made for the family, they cannot guarantee the existence of marriage for every. Once the building of marriage collapses, the status of women will also disappear. From this perspective, there is no solid foundation for the status of Japanese women. On the other hand, as a social person, women work not only for survival, but it is also a psychological demand, which can stimulates the potential and create talents, while the housework is generally tedious, which can eliminate the human creation. Therefore, for the female status from the perspective of psychological demand, it is also needed to take whether to get the right of working as the standard to measure the female status. More and more women in Japan have both their work and happy family, perhaps this is very difficult for the traditional Japanese women, but as long as they feel happy, it is enough. In China, it is harder for women to do housework and raise children than men to work, but they should also support the family together with men. Relatively, the Chinese women undertake more responsibilities of caring for the family than Japanese women. The Chinese women should both work and care family, if the husbands stand by in doing housework and raising children, it is unfair. Compared with the Japanese women, the Chinese women are far more hard working. From this perspective, are the Chinese women happy or poor?

\section{References}

[1] Chikako Terao, Change of Marriage Concept of Modern Japanese Women-Japanese Women 
influenced by Chinese Ideology, Collected papers of the $7^{\text {th }}$ marriage celebration culture of the south of Fujian on both sides of the Taiwan Strait [J], October 31, 2009

[2] Wang Xiaodong, Change in Marriage Concept of Japanese Women after the War, Journal of Changchun Normal University (human and social science edition) [J], September 20, 2010

[3] Yue Qian, Xue Kun, Exploration on Employment Status of Japanese Women and its Main Reasons, Century Bridge [J], May 1o, 2010

[4] Zhao Jing, Social Sex Labor Division and Living Model of Contemporary Women, Japanese Language Study and Research [J], October 25, 2009 